\title{
COMMUNICATION FORUM
}

\section{Commentary}

In the November 1987 issue of Management Communication Quarterly, Frank E.X. Dance concludes that behaviors for public and presentational speaking overlap, and any differences between them must be differences not of genre but of situation or setting. In response to Dance, this article examines pedagogical and linguistic literature to recommend the validity and value of adopting "presentational speaking" as a distinct genre or speaking type. In conclusion, the author suggests that treating public, presentational, and conversational speaking as distinct genres may spawn the development of theoretical models and pedagogical approaches more relevant to particular business speaking events.

\section{DISTINGUISHING PUBLIC AND PRESENTATIONAL SPEAKING}

\author{
Priscilla S. Rogers \\ University of Michigan
}

In the November 1987 issue of Management Communication Quarterly, Frank E.X. Dance discusses the meaning of presentational speaking, a term, he concludes, that has come to represent "public speaking in business settings." Dance writes:

In our time, the use of the term presentational for public speaking in the business setting is so deeply embedded in some organizations that there appears to be little likelihood of change in terminology in the near (or probably even in the distant) future. The controlling executive and managerial voices seem almost to be in unison on the topic-so why bother fighting it? (pp. 270-271)

Management Communication Quarterly, Vol. 2, No. 1, August 1988 102-115

() 1988 Sage Publications, Inc. 
Rather than "fight it," Dance suggests that the differences between public and presentational speaking, if they exist at all, are "expectational differences," that is, differences stemming from the business situation or setting (pp. 266, 270-271). To illustrate, Dance provides a comparative table listing twelve "expectational differences" (p. 268). Since business people persist in substituting the word presentation for the word public when they refer to speaking, Dance concludes, "we should know what expectational differences the business setting makes and how those differences are affected by public speaking scholarship and experience" (p. 270).

Dance's thought-provoking discussion recalls situations involving the selection and creation of teaching materials for business communication courses. Last summer our communication staff reviewed textbooks for a business communication course emphasizing speaking. One book was singled out by all the staff. Readable yet sophisticated in its integration of communication theory and practice, this text covered organizational, dyadic, group, and public communication, with concrete examples demonstrating author awareness of business communication issues. Although appreciated in many ways, this textbook was not selected because the section titled "Public Communication" and subsequent discussions of "public speaking" did not seem inclusive of the full range of business speaking experiences.

The inadequacy of the term public speaking, and its companion word speech, also became apparent when creating course materials. Over the last several years the word presentation has slowly replaced the word speech in syllabi for business school communication courses-"one-point speeches" are now "one-point presentations" "pro-con speeches" have become "pro-con presentations." This substitution of "presentation" for "speech" was admittedly more intuitive than reflective. For some reason, the term presentation seemed to describe more accurately the type of speaking assignments required of students in business communication classes.

By drawing attention to the growing use of "presentational 
speaking," Dance's article suggests why business communication materials and managerial communication seminars featuring "public speaking" seem askew. As the manager Dance quotes said, “Our people don't give public speeches. They give presentations" (p. 261). Among those who manage and those who teach management communication, there seems to be a growing awareness that business speaking events cannot be entirely defined by "public speaking," nor are the principles for the same entirely (or perhaps even desirably) applicable. Given the significance of this issue, Dance's ideas are critiqued and advanced with a review of pedagogical and linguistic sources that recommend the validity and value of regarding presentational speaking as a unique speaking type.

\section{"PRESENTATION" IN PEDAGOGY}

Dance examined pedagogical sources and found six applications of "presentation"(pp. 263-266). Presentation is used as

(1) a synonym for delivery,

(2) a type of speech such as a presentation of an award,

(3) a synonym for public speaking,

(4) a public speech in a business setting, usually presenting a new idea, a policy, or a procedure,

(5) an inclusive word representing all forms of business interchange (such as interpersonal and group communication), and

(6) a specific one-on-one situation in which a subordinate gives a report or an update to a superior.

Dance dismisses the sixth usage as "exotic." In summarizing his other findings, he writes:

Historically, presentation seems to have been introduced as an elliptical form for public speaking delivery in business settings and then became generalized to take the place of the label public speaking.... Certainly, at this stage there do not seem to 
be any substantive differences setting the business presentation apart from the general public speech (p. 265).

Dance concludes that "substantive differences" between public and presentational speaking are not found in pedagogical sources.

"Substantive differences" between public and presentational speaking are articulated in a number of pedagogical sources, however. In a 1940 article for The Quarterly Journal of Speech titled "Contemporary Trends in Business Speech,"William M. Timmons distinguishes public speaking from speaking events such as selling, making claim adjustments, giving oral reports to superiors, and giving oral instructions to subordinates. "We all know from casual observation," Timmons states, "that the business man (and all other people) most frequently participates not in public address but in what we often term, for want of more accurate terminology, 'private' or 'informal' speaking" (p. 412). "In contrast to public speaking," Timmons explains, "private speaking involves a relatively small group usually consisting of two to twelve members who frequently interact" (p. 412). Timmons concludes, "There is no doubt in my mind that ... there are important differences between what we term 'private' and public speaking, enough differences to warrant offering courses in each" (pp. 419-420).

What Timmons introduced as "private" or "informal" speaking in 1940, Howell and Bormann explicated as "presentational" speaking in 1971. In Presentational Speaking for Business and the Professions, they define a presentation as a "unique form of verbal communication" (p. 16). Distinct from public speeches (inspirational or public relations addresses, written more to please than to prompt change) or talks (informal remarks with little or no significance for decision making), presentations, Howell and Bormann suggest, are visualized, proposal-oriented speaking events designed for a select group of individuals who are inherently interested in their content (pp. 9-19). ${ }^{1}$ According to Howell and Bormann, presentations are 
(1) designed to prompt change and are central to decision making (pp. 10, 16),

(2) "complicated matters" for which the "facts of the case" are more persuasive than the "hard sell" (pp. 8, 18),

(3) immediately relevant for the receivers (p. 18),

(4) audience-centered or adapted to the personal interests of each receiver (pp. 16-17, 19),

(5) interactional, engaging the individual receivers continuously (pp. 6, 17),

(6) dependent to varying degrees on audiovisual aids (pp. 6, 12),

(7) extemporaneously delivered; "no paragraph is literally reproduced" (p. 6),

(8) given by one individual or a team of individuals to one or several different audiences (pp. 11-12).

Above all, Howell and Bormann suggest, presentations require an audience focus rather than a self focus. The "necessity to predict response," they contend, is the "frame of reference [by] which to analyze and develop a methodology of presentational speaking" (p. 18).

More recently, Thrash, Shelby, and Tarver have substantively distinguished public and presentational speaking in Speaking Up Successfully: Communication in Business and the Professions (1984). While they admit, to a greater extent than Howell and Bormann, that presentations share public speaking characteristics, Thrash et al. also advance essential differences. In fact, their book includes separate sections on speeches and presentations. Thrash et al. define presentation as "a specialized job-related talk designed to provide information or to persuade" and discuss six unique features (pp. 179, 181-183):

(1) Audiences for presentations are generally smaller than for speeches.

(2) Audiences for presentations usually include listeners with the power to decide and act upon recommendations.

(3) Detail is greater in presentations and therefore they tend to be longer than speeches. 
(4) Visual aids are used extensively in presentations.

(5) Questions may be asked at any time during presentations.

(6) More than one speaker may be involved in a presentation.

In contrast to Dance, for whom presentation is ultimately another name for a business speech with expectational differences, Timmons, Howell and Bormann, and Thrash et al. are among those who treat presentational speaking as a type of business speaking distinct from public speaking. ${ }^{2}$

\section{"PRESENTATION" AS GENRE}

Dance locates the distinction between public and presentational speaking in situation rather than in genre. He writes:

Neither the review of early and of current [pedagogical] writings in the area nor other considerations arising from a close examination of the two phenomena suggest any real differences between them. Thus any differences that do exist between public speaking and presentational speaking must be differences not of the genre but of the situation or setting (p. 266).

Dance's dismissal of generic distinctions may be premature. While linguists continue to struggle with the concept of genre, some respected linguistic definitions seem appropriate to the discussion of public and presentational speaking and suggest the validity of distinguishing them as types. Brown and Yule's discussion is especially apt. In Discourse Analysis (1983) they write:

In order to construct a notion of "genre," it is necessary to generalise across experience and determine what it is that is common to fairy stories, chats, news broadcasts, epic poems, debates or salesmen's routines which enables us to recognise one as being a token of the generalised type.

On the basis of experience then, we recognise types of communicative events which take place against the background 
of a mass of below-conscious expectations also based on past experience. (pp. 61-62; emphasis added) ${ }^{3}$

Using Brown and Yule's definition, Dance's article may be said to actually endorse the idea that public and presentational speaking are distinct genres. Dance seems to have generalized across experience to determine what it is that is common to presentations that distinguishes them from speeches. His analysis results in a list of "expectational differences," much like the characteristics proposed by Howell and Bormann and Thrash et al. (see Table 1).

The characteristics for presentational speaking proposed by Dance and others also recall Wittgenstein's "family resemblances" approach for categorizing types. In Philosophical Investigations (1958), Wittgenstein writes:

Consider for example the proceedings we call "games." I mean board-games, card-games, ball-games, Olympic games, and so on. What is common to them all?-Don't say: "There must be something common, or they would not be called 'games"'-but look and see whether there is anything common to all.-For if you look at them you will not see something that is common to all, but similarities, relationships, and a whole series of them at that. To repeat: don't think, but look!

And the result of this examination is: we see a complicated network of similarities overlapping and criss-crossing: sometimes overall similarities, sometimes similarities of detail. (pp. 31-32)

What Wittgenstein did with games, Howell and Bormann, Thrash et al., and Dance, do with public and presentational speaking. They have looked and seen characteristics common to presentations apart from characteristics common to speeches-characteristics that seem to qualify each as a generalized type.

That one individual's list of characteristics may vary from another's does not necessarily negate the idea that presentations and speeches are distinct genres. In fact, in discussing genre, 


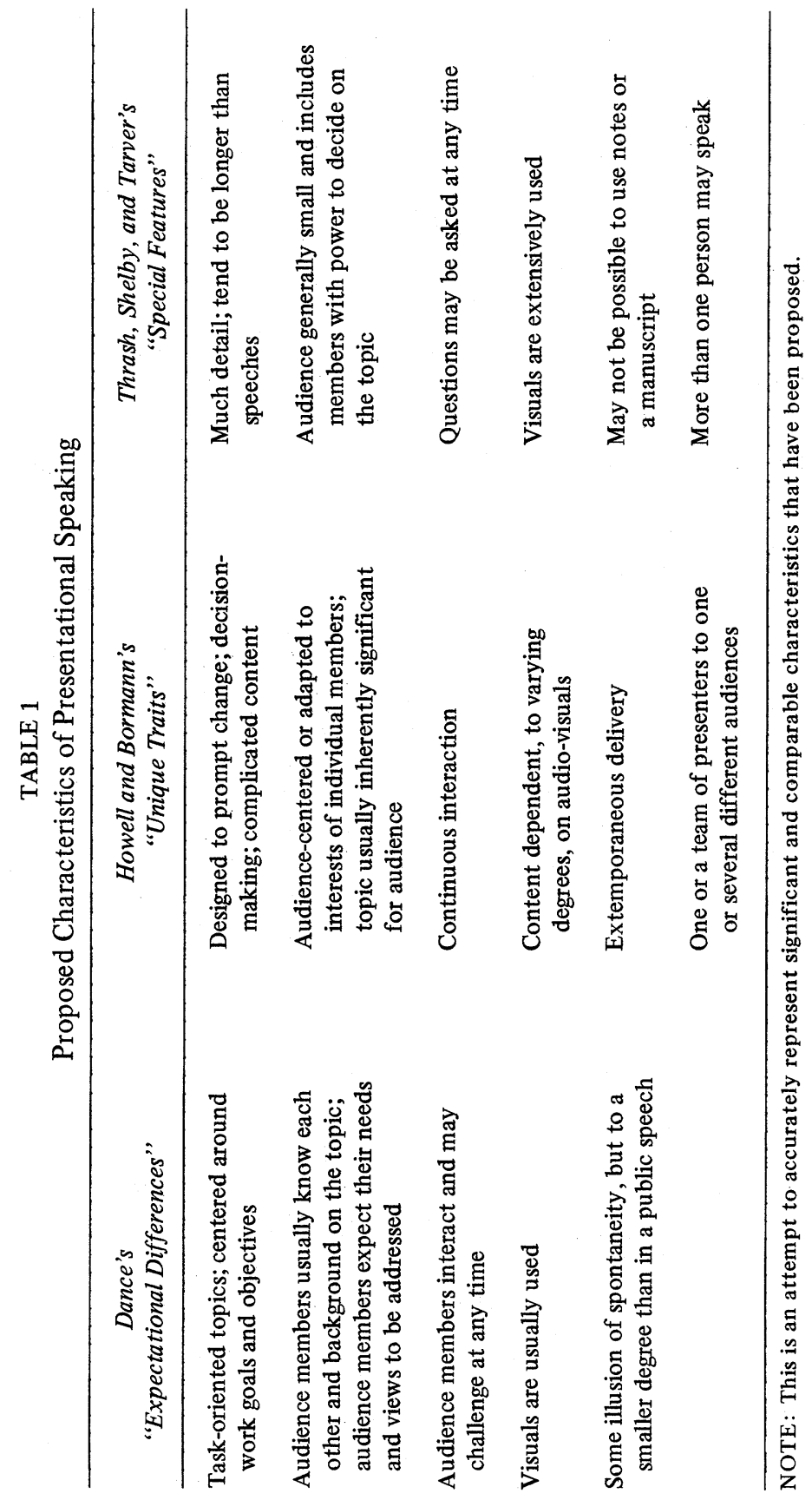


linguists point out the impossibility of precise definitions. "We can tell the difference between a comedy and a tragedy," writes Hawkes in Structuralism and Semiotics (1977), "even if those terms are not as precise and exclusive as we might wish them to be" (p. 101). Rather than depend on precise definitions for specific genres, some linguists would have us rely on the "intuition of experience." In The Ethnography of Communication: An Introduction (1982), Saville-Troike writes:

Since we cannot expect any language to have a perfect metalanguage, the elicitation of labels for categories of talk is clearly not adequate to assure a full inventory and must be supplemented by other discovery procedures, but it is basic to ethnography that the units used for segmenting, ordering, and describing data should be those of the group... and not a priori categories of the investigator. (p. 34; emphasis added)

As Dance reports (p. 270), "the group," or managers in some organizations, distinguish "presentations" and "speeches." It is perceived that something very different is happening when a field manager is promoting a sales plan before dealers than when she or he is introducing a district manager at a press conference. That some would call the former "a presentation" and the latter "a speech of introduction" may legitimize a generic distinction.

\section{VALUE OF "PRESENTATION" AS GENRE}

Regardless of what you call it, be it genre or type, treating presentational speaking as more than a mere synonym for public speaking is beneficial. Such a distinction expands the communication vocabulary, affording more differentiation between the speaking events in business. This expansion of language illustrates the range of communication competencies needed by business people. Moreover, acknowledging that, in addition to giving speeches and engaging in small talk, business 
people frequently make presentations, fills what appears to be a very large gap between public speaking and conversation.

The usefulness of "presentational speaking" as a third and intermediary speaking type may be demonstrated by considering the following speaking events:

- formal introductions

- sales pitches

- press statements

- recruiting luncheons

- elevator small talk

- personal tributes

- orientation events

- progress reports

- appraisal interviews

- briefing sessions

- presidential addresses

- explanation of policies, plans, or proposals

- chats at company parties

Public and conversational speaking seem appropriate labels for some of these events (Figure 1). ${ }^{4}$

Sales pitches, progress reports, briefing sessions, and explanations of policies, plans, or proposals are not as clearly identified as public or conversational speaking. In the past such speaking events have been dealt with in various ways. Often they are discussed in textbook sections on public communication where principles of public speaking are said to apply; sometimes they are distinguished as "job-related speeches" or "speeches in special circumstances." These treatments seem less appropriate than simply categorizing such speaking events as presentations, especially given the current use of the term as reported by Dance and as detailed by others (Figure 2).

If presentational speaking is treated as a genre, it may be developed as such, and fundamental characteristics may be identified. Some of the characteristics presently promoted are 


\begin{tabular}{ll}
\multicolumn{1}{c}{$\begin{array}{c}\text { Public } \\
\text { Speaking }\end{array}$} & \multicolumn{1}{c}{$\begin{array}{c}\text { Conversational } \\
\text { Speaking }\end{array}$} \\
formal introductions & recruiting luncheons \\
press statements & elevator small talk \\
personal tributes & appraisal interviews \\
presidential addresses & chats at parties
\end{tabular}

Figure 1: Categorized Speaking Events

too readily dismissed. One can, for example, dispute the idea that public speeches can be given anywhere, inside or outside, whereas presentations are usually given inside at some business site (Dance, p. 268). Upon further reflection, this distinction seems peripheral because one can think of speaking events that take place in a number of situations, apart from business sites, inside or outside, that seem more "presentational" than "public." Similarly disputable is the claim that, for public speeches, audiences may allow some deviation, whereas, for presentations, audiences usually expect close adherence to the announced topic (Dance, p. 269). Regarding presentational speaking as a distinct speaking type may prompt exploration of characteristics that are more clearly endorsed than negated by experience. Characteristics proposed by Howell and Bormann, Thrash et al., and Dance provide a beginning point. ${ }^{6}$

Adopting "presentation" as the generic representation for certain speaking events may spawn the development of theoretical models and pedagogical approaches more relevant to particular business speaking events. One wonders at the validity of applying public speaking theories and principles, which is so commonly done, to speaking situations that could be called presentational. In business communication courses and management training programs, principles of public speaking seem less and less applicable, as business and management practices are better understood. Accepting presentational speaking as a genre distinct from public or 
Public
Speaking

formal introductions press statements personal tributes presidential addresses
Presentational

Speaking

sales pitches

progress reports

briefing sessions

explanations of policies,

plans, and proposals

\section{Conversational}

Speaking

Figure 2: Categorized Speaking Events Including Presentations

recruiting luncheons elevator small talk appraisal interviews chats at parties

\title{
.
}

\begin{abstract}
conversational speaking may prompt exploration of the unique demands of speaking events such as reports, briefings, and explanations. Rather than accept presentational speaking as a synonym for "public speaking in the business setting" (Dance, p. 270), it is appropriate, useful, and perhaps even necessary, to regard presentations as a distinct speaking type.
\end{abstract}

\section{NOTES}

1. Howell and Bormann (1971) distinguish presentations from oral reports as well as from public speeches. Oral reports, they explain, are not as significant as presentations and are not as dependent on audiovisual aids (p. 12). Because Howell and Bormann focus on presentational speaking, they do not develop this distinction.

2. In Communicating at Work: Principles and Practices for Business and the Professions (1983), Ronald Adler also states that speeches and presentations are not identical. He describes "the speech" as a formal talk delivered to a large group, usually without interruption, and "the presentation" as a less formal talk given to a smaller group during which the speaker may answer and ask questions. While introducing the distinction, however, Adler does not develop it because, as he states, "in spite of their differences, speeches and presentations make many of the same requirements on a speaker" (p. 234). In Effective Speaking in Business (1955), Huston, Sandberg, and Mills distinguish public and conversational speaking from what they call "conference speaking." Similar to other definitions of presentational speaking, they define conference speaking as a dialogue, given in a business setting, with predetermined development of subject matter, but adapted to the questions raised by the one or few conferees (pp. 35-36).

3. I thank Professor John M. Swales for bringing this and some of the successive citations to my attention. 
4. Henry W. Taft is one of the early pedagogical writers to discuss the similarities and dissimilarities of public and conversational speaking in Kindred Arts: Conversation and Public Speaking (1929).

5. Typical of discussions on "job-related speeches" or "speaking in special circumstances" is Wayne Minnick's second edition of Public Speaking (1983).

6. It also might be useful to compare a speech to a letter, a presentation to a memorandum, and a conversation to a note.

\section{REFERENCES}

Adler, R. B. (1983). Communicating at work: Principles and practices for business and the professions. New York: Random House.

Brown, C., \& Yule, G. (1983). Discourse analysis. Cambridge: Cambridge University Press.

Dance, F.E.X. (1987). What do you mean presentational speaking? Management Communication Quarterly, 1, 260-271.

Hawkes, T. (1977). Structuralism and semiotics. Berkeley: University of California Press.

Howell, W.S., \& Bormann, E. C. (1971). Presentational speaking for business and the professions. New York: Harper \& Row.

Huston, A. D., Sandberg, R. A., \& Mills, J. (1955). Effective speaking in business. New York: Prentice-Hall.

Kendall, K. E. (1974). Do real people ever give speeches? Central States Speech Journal, 25, 233-235.

Minnick, W. C. (1983). Public speaking (2nd ed.). Boston: Houghton Mifflin.

Saville-Troike, M. (1982). The ethnography of communication: An introduction. Oxford: Blackwell.

Taft, H. W. (1929). Kindred arts: Conversation and public speaking. New York: Macmillan.

Thrash, A. A., Shelby, A. N., \& Tarver, J. L. (1984). Speaking up successfully: Communicating in business and the professions. New York: Holt, Rinehart \& Winston.

Timmons, W. M. (1940). Contemporary trends in business speaking. The Quarterly Journal of Speech, 26, 411-480.

Wittgenstein, L. (1958). Philosophical investigations (3rd ed.) (G.E.M. Anscombe, Trans.). New York: Macmillan.

Priscilla S. Rogers (Ph.D., University of Michigan) is Assistant Professor of Communication at the University of Michigan School of Business, where she is Director of the M.B.A. Writing Program, a program she designed in 1986. She is also Coordinator of the B.B.A. core course in communication. She has taught every business communication course at the University of Michigan School of 
Business, all of which involve presentational speaking. She has designed and implemented communication training programs for the automotive industry and medical managers. Her research interests are the nature of communication context, more specifically, the development of tools for evaluating communication context and competencies needed in particular contexts. 